\title{
Technology Transfer Opportunities: New Development USGS Mini Image Processing System
}

\begin{abstract}
About the System
The U.S. Geological Survey's Mini Image

Processing System (USGS MIPS) is a public domain, full-featured software package with the ability to process and analyze remotelysensed data. This includes: Landsat TM, Landsat MSS, Spot, AVHRR, radar, and sonar images. Other data, such as digitized aerial photographs, digital elevation models, and magnetics, gravity, and resistivity data can also be processed.
\end{abstract}

\section{MIPS Processing Categories}

The following are the major processing categories available in USGS MIPS:

analysis and enhancements

spatial filtering

import and export utilities

radiometric corrections

statistical utilities

vector processing

classification/clustering

geometric corrections

interactive display and analysis

sonar processing

general utilities

\section{MIPS Image Processing Programs}

The current version of USGS MIPS consists of $100+$ individual programs. Some examples of image processing programs include:

multispectral ratios

hue-intensity-saturation transforms

low/high pass filtering

cubic convolution resampling

spatial variability analysis vector-to-raster conversion

principal component analysis

unsupervised classification

haze/sun angle radiometric corrections

nearest neighbor resampling

multivariate statistics

\section{Platforms}

USGS MIPS was designed as an office research and development image processing system. Its original inception was in 1980 on a PDP $11 / 23$. In 1986, USGS MIPS was ported to the VAX/VMS environment. In mid-1992, the porting of USGS MIPS to computer platforms supporting $\mathrm{X}$ windows and Motif began. As of February 1996, USGS MIPS is supported on the following hardware platforms. Note that all platforms require an ANSI $\mathrm{C}$ and Fortran compiler.
DEC Alpha running Digital Unix
DEC Alpha running OpenVMS
Data General running Dgux
Sun running Solaris

\section{For More Information}

For more information about USGS MIPS or to download the latest distribution, see the MIPS website at

\section{http://wwwllag.wr.usgs.gov/trs/software/mips}

The site includes complete installation instructions given under on-line documentation.

Questions, comments, or additional information can be addressed by sending email to usgsmips@goblin.wr.usgs.gov

Although the USGS MIPS software package has been used by the USGS, no warranty, expressed or implied, is made by the USGS as to the accuracy and functioning of the package and related material nor shall the fact of distribution constitute any such warranty, and no responsibility is assumed by the USGS in connection herewith. Any use of trade names and trademarks in these pages is for identification purposes only and does not constitute endorsement by the USGS. 
